\title{
A pesquisa acadêmica como atividade humana: participaçáo de usuários da saúde mental e as contribuiçóes da Terapia Ocupacional
}

\author{
Tatiana Dimov ${ }^{\mathrm{a}}$, Ellen Cristina Ricci ${ }^{\mathrm{b}}$

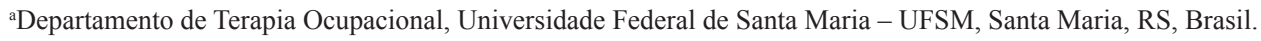 \\ bDepartamento de Saúde Coletiva, Universidade Estadual de Campinas - Unicamp, Campinas, SP, Brasil.
}

\begin{abstract}
Resumo: A participação de usuários em pesquisas é uma tendência recente no mundo. Pesquisas deste tipo enfocam serviços de saúde, abordagens terapêuticas, efetividade de grupos de apoio e ajuda mútua, e medicação. Essas pesquisas são fundamentais para a obtenção de resultados acadêmicos que sejam representativos do grupo de usuários, além de influenciar políticas públicas que sejam efetivas e funcionais para os mesmos. Este artigo apresenta uma análise sobre como pode se dar a participação de usuários de serviços de saúde mental em pesquisas e qual pode ser o papel do(a) terapeuta ocupacional nesta construção. Percebe-se, nestes processos, quando regidos pelos princípios de autonomia, empoderamento e recovery, que vão ao encontro dos princípios de igualdade e reconhecimento, na medida em que possibilita não só a inserção no processo de pesquisa, mas também a possibilidade de vivenciar uma relação de igualdade pautada na valorização da experiência e no reconhecimento do saber dos usuários. A atividade de pesquisa pode ser um agente motivador, que mobiliza vontades, desejos, além da possibilidade de o sujeito sair da estagnação e tomar decisões. Dentro desse processo relacional, o(a) terapeuta ocupacional pode co-construir ou reconstruir a ação dos sujeitos no mundo. Entendendo que a terapia ocupacional tem como objeto de trabalho as atividades que são significativas na vida do indivíduo, a participação em pesquisa se transforma em foco para o processo terapêutico, na medida em que isso se apresenta enquanto demanda para e do próprio sujeito em questão.
\end{abstract}

Palavras-chave: Terapia Ocupacional, Saúde Mental, Avaliação de Serviços de Saúde, Sujeitos da Pesquisa, Participação Comunitária.

\section{Academic research as human activity: Occupational Therapy contributions for consumer participation}

\begin{abstract}
The involvement of consumers in research is a recent trend in the world. Involving consumers in researches on health services, therapeutic approaches, effectiveness of support groups, mutual help groups, and even on medication is crucial for obtaining academic results that are representative of the group of consumers, and influence public policies that are effective and functional for consumers. This paper presents an analysis of how consumers can get involved in a research and what can be the role of an occupational therapist in such activity. When governed by the principles of autonomy, empowerment, and recovery, researches with consumer participation promote the principles of equality and recognition, allowing inclusion in the research process, and promoting the recognition of consumer knowledge. As an activity, research can be a motivator, mobilizing wills and desires. It can also be a possibility of leaving stagnation and making decisions. The occupational therapist can help this process. Occupational therapy focus on activities that are significant to the life of individuals. Participation in research becomes a focus for the therapeutic process to the extent that it presents itself as a demand for the client.
\end{abstract}

Keywords: Occupational Therapy, Mental Health, Health Service Evaluation, Research Subjects, Consumer Participation.

Autor para correspondência: Ellen Cristina Ricci, Laboratório Saúde Coletiva e Saúde Mental, Universidade Estadual de Campinas, Rua Tessália Vieira de Camargo, 126, Cidade Universitária Zeferino Vaz, CEP 13083-887, Campinas, SP, Brasil, e-mail: ellenricci@gmail.com

Recebido em Maio 24, 2015; $1^{\text {a }}$ Revisão em Ago. 20, 2015; $2^{\text {a }}$ Revisão em Out. 24, 2015; $3^{\text {a }}$ Revisão em Nov. 16, 2015 ; Aceito em Nov. 23 , 2015. 


\section{Introdução}

A participação de usuários em pesquisas é uma tendência recente, não só no Brasil, mas em países como Austrália, Canadá, EUA, Reino Unido e Nova Zelândia. Entende-se que este tipo de participação em pesquisas sobre serviços de saúde, abordagens terapêuticas, efetividade de grupos de apoio e ajuda mútua, e até sobre a medicação, é fundamental para a obtenção de resultados científicos que sejam representativos do grupo de usuários, além de influenciar políticas públicas que sejam efetivas e funcionais para o grupo de pessoas atendidas.

Dantas e Oda (2014), em artigo sobre estudos e publicações referentes à avaliação de serviços de saúde mental no Brasil, realizaram levantamento bibliográfico através do Banco de Teses da Coordenação de Aperfeiçoamento de Pessoal de Nível Superior (Capes) e a Biblioteca Virtual em Saúde (BVS), e identificaram que, no período de 2004 a 2013, em apenas $12(17,6 \%)$ das dissertaçôes e teses, os usuários foram a principal e única fonte de informação. Para artigos, as pesquisadoras ampliaram a busca para outras fontes (Scielo, Scopus e Google Acadêmico) e encontraram usuários como grupo único ou em conjunto com outros informantes em 34 artigos $(33,1 \%)$ e, em 16 artigos (15,5\%), estavam envolvidos concomitantemente trabalhadores de saúde mental, usuários diretos dos serviços e familiares de usuários.

Dentro do cenário brasileiro, percebe-se a escassez de trabalhos que valorizam a voz do usuário como principal informante e avaliador dos serviços. Posto isto, o presente artigo visa a apresentar uma reflexão acerca das possibilidades e limitaçôes do papel do(a) terapeuta ocupacional junto a usuários de serviços de saúde mental que participam de pesquisas acadêmicas.

\section{Sociedade Civil e Conhecimento}

Em sociedades descentralizadas e pluralistas, existem diversas esferas públicas, as quais se articulam em torno de temas comuns, círculos políticos ou pontos de vista funcionais (HABERMAS, 1997). A esfera política pública faz-se presente em domínios diversos, estendendo-se desde ambientes de livre convivência até encontros organizados por associações e movimentos sociais, sendo

[...] uma estrutura intermediária entre o sistema político, de um lado, e os setores privados e os sistemas de ação especializados em termos de funções, do outro lado [...] (HABERMAS, 1997, p. 107).

O debate nessas esferas caracteriza-se pela dialogicidade, pela "liberdade comunicativa", concedida por ambas as partes. Dentre essas diversas esferas públicas, Habermas (1997) considera que a sociedade civil tem melhor capacidade para captar problemas específicos que afetam indivíduos e grupos, uma vez que possibilita o caráter espontâneo do discurso, fora da arena política convencional ou formal.

Castells (1997) ressalta a importância dos movimentos sociais enquanto forma legítima de organização da sociedade civil, entendendo que o caráter espontâneo do discurso nessas esferas de discussão possibilita a revitalização de práticas e instituições democráticas. Desta forma, a sociedade civil contribui para a ampliação do debate na esfera pública, buscando soluçôes alternativas a problemas comuns.

Habermas (1998) apresenta, em sua teoria, o rompimento com a perspectiva elitista de que a racionalidade é produzida por um grupo determinado, sendo assim ancorada em práticas públicas de discussão. Assim, o sujeito é levado a oferecer as razóes que significam suas açôes de forma a apresentar aos demais uma explicação através de um discurso, que é publicamente compartilhado. Para o autor, a mudança na ordem social depende da ação coletiva e, principalmente, de atores sociais competentes, com capacidade de aprendizagem social. A opinião pública, resultado do processo de discussão coletiva, subsidia as tomadas de decisôes nas instâncias formais, democraticamente constituídas, do sistema político.

Diante disso, usuários de serviços de saúde mental são entendidos aqui como um dos grupos que disputam o espaço público, ao reivindicarem sua inserção na sociedade, com certas características e representaçóes socialmente sustentadas. As normas que orientam a convivência social de tais grupos estão relacionadas às normas de solidariedade coletiva, conforme expressas em práticas sociais compartilhadas (HONNETH, 1999).

Ao buscar o ideal da autonomia e ampliação de oportunidades de escolha daqueles que vivem a experiência de adoecimento mental, o Movimento Antimanicomial evidencia como a identidade coletiva encontra-se imbricada às identidades individuais. Para que esses sujeitos tenham efetivas condiçōes de vivência da autonomia, de definir o que fazer, desde o intercâmbio econômico, profissional, médico-hospitalar até as relaçôes de amor e amizade, é necessário que as condiçôes para autodefinição individual sejam sustentadas em seu entorno, tanto pela rede de serviços que o acompanha quanto nas relaçóes que 
acontecem nos diversos ambientes da sociedade, públicos e privados (MÂNGIA; NICÁCIO, 2001).

Nesse sentido, a participação de usuários de serviços de saúde mental em pesquisas, regidas pelos princípios de autonomia, empoderamento e recovery, parece ir ao encontro de princípios de igualdade e reconhecimento, na medida em que possibilita não só a inserção no processo de pesquisa, mas também a possibilidade de vivenciar uma relação de igualdade, pautada na valorização da experiência e no reconhecimento do saber dos mesmos. No entanto, a existência de tais experiências no Brasil é recente e carece de estudos que forneçam indicadores quanto à efetividade da inclusão social deste grupo populacional.

\section{Participação de Usuários em Pesquisa}

$\mathrm{Na}$ literatura internacional, há um crescente reconhecimento da importância, do direito e do valor do envolvimento de usuários da saúde mental em pesquisa (ROSE, 2003; GRIFFITHS; JORM; CHRISTENSEN, 2004; HAPPELL; ROPER, 2007; HOPKINS, 2008; NING; WEAVELL; WOODHOUSE, 2010; WOODALL; HOWAR; MORGAN, 2011; HANCOCK et al., 2012). Embora seja reconhecida a importância da inclusão ativa dos mesmos em pesquisa, valorizando o conhecimento advindo da experiência vivida, ainda são raras as iniciativas que os incorporam na equipe de pesquisa, como pesquisadores e/ou colaboradores. Hancock et al. (2012) apontam para o fato de que, embora seja crescente o número de publicações que valorizam esse tipo de parceria, poucas são as publicaçôes reconhecidas como científicas, nas quais a participação de usuários de fato aconteceu.

No Brasil, a literatura sobre participação de usuários em pesquisas acadêmicas é limitada, sendo escassas e recentes as experiências de inserçáo de usuários em pesquisa, relatadas na literatura científica e mapeadas por nós (FURTADO; CAMPOS, 2008; VASCONCELOS, 2013; PRESOTTO et al., 2013).

Países, como Austrália e Nova Zelândia, incorporaram a participação de usuários da Saúde Mental em pesquisa enquanto direito dos mesmos. Happell e Roper (2007) colocam que o envolvimento deles é positivo para o desenvolvimento da própria pesquisa, permitindo abordagens mais inclusivas quanto ao desenho, à conduta e à interpretação dos dados; geram resultados mais proveitosos para a população atendida; a formulação de perguntas e as escolhas metodológicas tornam-se mais adequadas a partir da contribuição singular feita pelos membros da comunidade; o relacionamento entre pesquisadores acadêmicos e comunitários ${ }^{1}$ possibilita o desenvolvimento profissional dos acadêmicos; pesquisas com relaçóes mais horizontais entre pesquisadores e usuários resultam em maior credibilidade para a pesquisa entre a base do grupo de usuários; trata-se de uma valorosa oportunidade para que os pesquisadores comunitários desenvolvam novas habilidades de pesquisa. Aliado a isso, o envolvimento de usuários ajuda na adesão de outros pares para a pesquisa, além de diminuir o risco de abandonos.

Woodall, Howar e Morgan (2011) estudaram as razóes que levavam os usuários ao engajamento em pesquisa, sendo que as principais razóes apresentadas foram: 1) Incentivos práticos (preencher o tempo, oportunidade para sair da enfermaria, remuneração, alimentação e transporte); 2) Curiosidade; 3) Comunicação (explicaçóes sem jargóes técnicos, pesquisadores amistosos e profissionais, pesquisa de natureza voluntária); 4) Percepção da pesquisa como potencialmente útil (para aprender, para obter algo positivo de uma experiência negativa ou para conversar com outras pessoas sobre a própria experiência); 5) Ajudar os outros (ajudar os pesquisadores ou ajudar os outros usuários); 6) Experiências positivas com médicos; 7) “Timing” da abordagem, a qual não deve ser muito próxima à internação.

Encontramos, na literatura, fatores que se constituem enquanto barreiras neste tipo de participaçáo. Woodall, Howar e Morgan (2011) apontam os seguintes fatores que podem dificultar esse processo de inclusão: 1) preocupaçóes relacionadas a possíveis efeitos colaterais (medo de que falar sobre o assunto impeça de seguir em frente, possa ter efeitos colaterais ou atrapalhe o processo de recuperação/restabelecimento, de alguma forma); 2) barreiras práticas, como falta de tempo, sessões de pesquisa muito longas, não ter com quem deixar as crianças; 3) "timing" do convite: quando o convite para participação é feito logo após o início do tratamento; 4) quando o participante discorda de questóes conceituais sobre a doença mental, como os sintomas, por exemplo; 5) influência de outros usuários.

Happell e Roper (2007) apontam ainda a problemática da descrença, por parte de alguns pesquisadores, que náo valorizam ou encorajam a participação dos membros da comunidade, chegando, em alguns casos, a argumentar que os mesmos não são capazes de fazer pesquisa unicamente com base no diagnóstico. A falta de habilidades acadêmicas dos usuários, principalmente quando comparados aos pesquisadores, se configura enquanto fator que 
dificulta inserção dos mesmos em pesquisa, que, sem experiência e habilidades para a pesquisa, correm o risco de sofrer criticismo e "tokenism" (HAPPELL; ROPER, 2007; HANCOCK et al., 2012).

Ning, Weavell e Woodhouse (2010) ressaltam que os usuários, quando participam de pesquisas, tendem a propor questôes relevantes, identificar falhas na pesquisa; são bons indicadores da validade de determinados protocolos; oferecem interessantes interpretaçôes dos resultados, e acompanham a implementação dos resultados. Apesar da importância atribuída à sua participaçáo, existem diferentes entendimentos de como esta deve se dar (HAPPELL; ROPER, 2007). Rose (2003) propóe quatro níveis de envolvimento de usuários em pesquisa ${ }^{3}$ :

1. Supervisão de usuários (Consumer advisory): é o mínimo envolvimento em pesquisa. Quando os usuários são convidados a representar um grupo de stakeholders ${ }^{4}$ em grupos, como, por exemplo, um comitê que acompanha a pesquisa. Há pouco envolvimento no desenho da pesquisa, na conduta e na análise dos dados. O impacto da participação na pesquisa é mínimo, dado que eles costumam se constituir enquanto minorias nesses comitês, uma vez que é hábito serem remunerados pela participação e as pesquisas não conseguem verba para remunerar a participação de muitos usuários.

2. Consulta a usuários (Consumer consultation): processo pelo qual são consultados para aconselhamento sobre temas específicos, acerca dos quais a equipe de pesquisa reconhece sua experiência vivida. Embora a equipe reconheça que existe um saber que advém da experiência, a participação se dá de forma pontual, representando um pequeno impacto na condução da pesquisa.

3. Colaboração de usuários (Consumer collaboration): quando há colaboração entre pesquisadores, usuários e não usuários em todas as etapas da pesquisa, o que inclui a formulação da questáo de pesquisa, a escolha da metodologia, o processo de análise e as escolhas referentes à forma de divulgação dos resultados. Se não houver participação dos usuários em alguma etapa da pesquisa, ele náo pode ser entendido como colaborativo.

4. Liderada por usuários (Consumer ledinvolvement): quando todas as etapas da pesquisa são lideradas por usuários. Pesquisadores não usuários podem participar eventualmente de algumas etapas da pesquisa, mas isso se daria apenas sob a coordenação dos usuários que conduzem os trabalhos.

Hopkins (2008) coloca que, na mesma medida em que muitos usuários gostariam de entender e contribuir com sua experiência para pesquisas, para muito além de participar de um comitê de ética, os pesquisadores também buscam o suporte comunitário para embasar e legitimar suas pesquisas. Happell e Roper (2007) ressaltam que este tipo de envolvimento é um processo empoderador, que permite aos usuários um amadurecimento na construçáo da própria pauta de reivindicaçóes, influenciando a política pública, a configuração dos serviços de saúde e as práticas de atenção em saúde mental. No entanto, práticas inapropriadas de condução destas pesquisas, com envolvimento mínimo dos usuários, podem acarretar a formulação de perguntas equivocadas, a escolha de metodologias inadequadas e a interpretação enviesada dos dados, podendo acarretar a formulação de políticas públicas não condizentes às necessidades deste grupo populacional.

Griffiths, Jorm e Christensen (2004) colocam ainda que o diagnóstico psiquiátrico não se constitui enquanto critério que determina as habilidades de um determinado indivíduo para o desenvolvimento de pesquisas acadêmicas e ressaltam que, dada a alta incidência de transtornos mentais na população, é possível que muitos pesquisadores sejam também usuários, mas não abram esta condição enquanto pesquisadores, por medo do estigma e do preconceito.

Ning, Weavell e Woodhouse (2010) ressaltam que, apesar de haver problemas na inserção dos usuários em pesquisa, esta vem se constituindo enquanto uma prática que dá voz aos mesmos e às suas necessidades; no entanto, ressaltam que, para o sucesso da pesquisa, é necessário que os suportes corretos sejam dados e que a comunidade acadêmica se disponha a rever suas práticas, a fim de poder incorporar pesquisadores comunitários.

Colocamos a importância em reconhecer nos participantes de pesquisas mais suas potências do que suas dificuldades, que eles sejam encorajados a tomar decisóes sobre a participaçáo para além do enfoque no treinamento. Os pesquisadores comunitários deveriam ter acesso a recursos apropriados, como orientação, e os comitês de ética deveriam valorizar a experiência de vida.

\section{Terapia Ocupacional na Ação}

Benetton (2001, p. 147) coloca que "[...] a terapia ocupacional tem como propósito final a inclusão social [...]", visando à autonomia e à participação social; 
assim, o terapeuta ocupacional trabalha atividades significativas no contexto de vida de cada sujeito (YOUNGSTROM, 2002). É o próprio sujeito quem define o que é, para si, uma atividade significativa, pois este entendimento encontra-se no escopo de suas experiências subjetivas, de seus afetos e interesses, e de seu contexto cultural, político e social.

Cabe ao(à) terapeuta ocupacional, a partir do que foi identificado como significativo para cada sujeito ou grupo, potencializar a autonomia e a inserção social dos mesmos. Neste sentido, na medida em que a participaçáo em pesquisas constitui-se enquanto atividade significativa para um indivíduo ou grupo, é papel deste profissional intervir, promovendo a autonomia e a inserção social também nesta esfera, pois a TO está intensamente envolvida com a produção da vida e de modos de ser e estar no mundo, em que a vida humana constitui-se "num continuum de atividades" (QUARENTEI, 2001).

Hancock et al. (2012), entendendo que a participação em atividades significativas se constitui como parte do escopo de trabalho da terapia ocupacional, propóem que o desenvolvimento de habilidades para a participaçáo em pesquisas acadêmicas possa ser enfoque dos atendimentos. Dessa forma, os autores realizaram com usuários de um serviço de saúde australiano a construção conjunta de um guia de treinamento para o aprimoramento de habilidades em pesquisa, focando principalmente nas habilidades de entrevistas entre pares. Os resultados obtidos apresentam evidências de que os usuários podem melhorar o desempenho nas entrevistas entre pares através deste tipo de iniciativa.

No entanto, é necessário cuidado ao entender o espaço acadêmico enquanto espaço democrático e, portanto, catalizador do processo de inclusão do grupo de usuários. Fraser (1995) aponta para o potencial reprodutor das desigualdades sociais que alguns espaços tidos como democráticos vêm reproduzindo, no coletivo, desigualdades de gênero, raça e classe. Tal observação torna-se pertinente dentro dos espaços em que se fazem presentes usuários, trabalhadores, familiares e pesquisadores da saúde mental. Nestes, muitas vezes, a pauta e a fala dos usuários se diluem em meio às falas e pautas de estudantes e pesquisadores. Este tensionamento é presente na maior parte das associaçóes de usuários brasileiras, dependentes da presença de trabalhadores da saúde mental para a manutenção de seu funcionamento (VASCONCELOS, 2013) e pode se repetir nas relaçôes entre usuários e os pesquisadores.

É na teoria construída acerca do papel da Terapia Ocupacional que encontramos respaldo para refletir sobre o potencial de ação do(a) terapeuta ocupacional no contexto aqui apresentado. Embora a temática do envolvimento dos usuários da saúde mental possa causar uma primeira impressão de que esta seria uma temática inerente somente ao campo da saúde mental, gostaríamos de salientar que existem aspectos que caracterizam a populaçáo que hoje se define como usuária (que são, na verdade, usuários do Sistema Único de Saúde, o SUS), que estão para muito além de aspectos clínicos ou diagnósticos, mas que dizem de uma realidade sociocultural vivenciada e de um tipo de relação que se estabelece entre estes e aqueles que se identificam com as categorias "trabalhador" ou "pesquisador".

Barros, Ghirardi e Lopes (2002) colocam a necessidade de uma postura crítica na atuação da terapia ocupacional, salientando o risco de que, a partir do momento que o foco da atuação da TO passa a ser o de adequar os sujeitos a uma norma ou padrão, a atuação tem um potencial que é mantenedor do status quo. As autoras ressaltam a importância de que haja uma compreensão, por parte dos(as) terapeutas ocupacionais, da realidade social vivenciada pela população atendida. Para as autoras:

O conceito de atividade em terapia ocupacional social é um construto, uma mediação de relaçóes múltiplas, mas situada no tempo e no espaço cultural; é um conceito inacabado e incorpora em si essa incompletude, constituindo-se pelo movimento, pelo processo de comunicação em linguagem [...]. Tais atividades são objeto que se constrói na comunicação, na experiência e na situação vivida segundo a história, às práticas sociais e os valores culturais que cada pessoa ou grupo social realiza de forma particular (BARROS; GHIRARDI; LOPES, 2002, p. 102).

Barros, Ghirardi e Lopes (2002) destacam ainda a necessidade de que a ação da TO social promova descentramento:

1. do saber técnico para a ideia de saberes plurais, diante de problemas e questóes sociais;

2. das açóes da pessoa (considerado corpo/mente doente ou desviante) para o coletivo, a cultura da qual a pessoa náo pode ser separada;

3. da ação: do enquadramento (setting) para os espaços da vida cotidiana;

4. do conceito de atividade como processo individual para inseri-lo na história e na cultura de um grupo ou de uma pessoa (BARROS; GHIRARDI; LOPES, 2002, p. 100). 
Desta forma, para além do "treinamento" para a participaçáo em pesquisa proposto por Hancock et al. (2012), a participação de usuários de serviço de saúde mental em pesquisas pode ou não ser objeto de intervenção em terapia ocupacional, na medida em que há uma compreensão desta demanda. O que significa para os atores em questáo participar de uma pesquisa? Que sentido essa prática tem em suas vidas? Em que medida a participação é emancipadora? E em que medida ela é reprodutora de estruturas sociais de dominaçáo, que aprisionam os sujeitos? Perguntas como estas são importantes diante do entendimento de que o aspecto político deve ser incorporado ao cotidiano de trabalho do(a) terapeuta ocupacional, de modo que o profissional possa ser capaz de, como coloca Malfitano (2005), estabelecer um diálogo entre a microestrutura e a macroestrutura, contextualizando abordagens individuais dentro de um coletivo.

Rahman (1986) parte da premissa de que a ciência deve ser propositiva, com intenção de modificar a realidade, e deve unir-se a esforços para isso, o que significa que a pesquisa deve ser ideologicamente direcionada. O autor critica a ideia de que o povo não é capaz de sistematizar o próprio conhecimento e coloca que a validação do conhecimento acadêmico vem a ser mais uma forma de dominação. Neste sentido, é fundamental o desenvolvimento de uma forma popular de sistematização do conhecimento, para que não se crie uma estrutura de dominação pelo saber.

Na metodologia de Pesquisa Ação Participante (PAP), encontramos consonância com os princípios elencados por Barros, Ghirardi e Lopes (2002) para a terapia ocupacional social. Para Rahman (1986), a epistemologia da PAP corresponde ao pragmatismo e ao materialismo dialético. $\mathrm{O}$ autor coloca ainda que, na PAP, o grupo "pesquisado" torna-se também pesquisador, de modo a formar-se um coletivo de pesquisa que partirá de algum problema vivido pelo grupo e realizará então uma pesquisa que visa ao entendimento do problema em questão e à busca de soluções para o mesmo.

A PAP visa que, ao final do processo, haja algum tipo de transformação do grupo envolvido, gerando assim a solução para o problema em questáo, conforme os objetivos específicos da pesquisa. Por esse motivo, durante um determinado estudo, poderáo ocorrer ajustes progressivos nos planejamentos da investigação, se assim for necessário, "[...] fortalecendo a questão da pesquisa com ação [...]” (FRANCO, 2005, p. 496). Para este tipo de pesquisa, "[...] a participação das pessoas implicadas nos problemas investigados é absolutamente necessária [...]" (THIOLLENT, 2005, p. 17), havendo assim "[...] uma ampla e explícita interação entre pesquisadores e pessoas implicadas na situação investigada [...]" (THIOLLENT, 2005, p. 18). Desta interação é que serão tomadas as decisóes quanto aos rumos a serem empregados para que, enfim, os objetivos da pesquisa possam ser alcançados.

O papel do(a) terapeuta ocupacional não deve ser o de "adequar" os usuários ao saber acadêmico, mas sim trilhar, com este usuário, caminhos em que seu conhecimento, que parte da experiência, possa dialogar com os saberes acadêmicos. Não se trata também de supervalorizar a experiência e o saber dos usuários, ignorando todo o saber acadêmico. Freire (2002) coloca que é papel do educador desafiar o educando no sentido de produzir uma compreensão daquilo que é comunicado, colocando a importância da dialogicidade no processo de troca de saberes. Neste sentido, propomos, dentro de uma perspectiva freiriana, a possibilidade de um diálogo e a necessidade de percorrer com o usuário o caminho para o empoderamento, até que ele se veja em pé de igualdade para estar neste diálogo.

A atividade de pesquisa pode ser um agente motivador, que mobiliza vontades, desejos, possibilidade de o sujeito sair da estagnação e tomar decisóes. Dentro desse processo relacional, o(a) terapeuta ocupacional pode co-construir ou reconstruir a ação dos sujeitos no mundo, como sugere Malfitano (2005). Além disso, vista enquanto atividade fora do setting e inserida no contexto social, a inserção ativa dos usuários em pesquisas que se proponham a ser participativas pode ser transformadora do lugar social ocupado por estes sujeitos, que se deslocam do lugar de "usuário" - que carrega uma história de sofrimento, um diagnóstico (ou rótulo), uma relação com um serviço e com uma comunidade - para o lugar de "pesquisador", possibilitando outro olhar para a inserção social deste indivíduo $\mathrm{A}$ atividade passa então a servir como meio possível para a co-construçáo de novos projetos de vida, vista em um contexto que visa ao fortalecimento das redes do indivíduo e que fortalece sua autonomia no contexto no qual está inserido.

\section{Conclusão}

Entendendo-se que a terapia ocupacional tem como objeto de trabalho as atividades que são significativas na vida do indivíduo, a participação em pesquisa se transforma em foco para o processo terapêutico, na medida em que isso se apresenta enquanto demanda para e do próprio sujeito em questão. 
Lopes e Silva (2007, p. 158) chamam a atenção para o fato de que a

[...] terapia ocupacional espelha o que seus profissionais pensam e produzem e a forma como se posicionam politicamente frente às questốes sociais que a eles se colocam [...].

Entendendo-se que a clínica não é neutra, assim como a ciência também não o é, e que pesquisas e intervençôes terapêuticas partem de uma visão de mundo e de um posicionamento político, propomos aqui que o papel do(a) terapeuta ocupacional junto a usuários que participam de pesquisas em saúde mental seja o de valorização do conhecimento que parte da experiência, de facilitador, pensando formas e estratégias de potencializar o diálogo, e de catalisador, no processo de empoderamento do próprio usuário no processo de valorização do seu saber.

A terapia ocupacional, concebendo as atividades como territórios existenciais, pode potencializar os efeitos dos encontros dos usuários, pesquisador e pesquisado, para instituir processos de experimentaçáo, apreciação e afirmação de construção de si em uma nova ação potente e criadora de novas formas de relacionar-se no mundo. Cuidar desses encontros, fortalecê-los e ampliar o repertório dos usuários são as nossas perspectivas de trabalho, emancipadoras dos sujeitos, das práticas de pesquisa e das instituiçôes, com estas envolvidas, no Brasil.

\section{Referências}

BARROS, D. D.; GHIRARDI, M. I. G.; LOPES, R. E. Terapia Ocupacional Social. Revista de Terapia Ocupacional da Universidade de São Paulo, São Paulo, v. 13, n. 3, p. 95-103, 2002.

BENETTON, M. J. Terapia Ocupacional e reabilitação psicossocial: uma relaçấo possível? In: PITTA, A. (Org.). Reabilitação psicossocial. São Paulo: Hucitec, 2001. p. 143-149.

CASTELLS, M. The power of identity. Massachusetts: Blackwell, 1997.

DANTAS, C. R.; ODA, A. M. G. R. Cartografia das pesquisas avaliativas de serviços de saúde mental no Brasil (2004-2013). Physis: Revista de Saúde Coletiva, Rio de Janeiro, v. 24, n. 4, p. 1127-1179, 2014.

FRANCO, M. A. S. Pedagogia da pesquisa-açâa. Revista Educação e Pesquisa, São Paulo, v. 31, n. 3, p. 483-502, 2005.

FRASER, N. Rethinking the public sphere - a contribution to the critique of actually existing democracy. In: ROBBINS, B. (Org.). The Phantom Public Sphere. Minnessota: University of Minnessota Press, 1995. p. 1-32.
FREIRE, P. Pedagogia da Autonomia: saberes necessários à prática educativa. Rio de Janeiro: Paz e Terra, 2002.

FURTADO, J. P.; CAMPOS, R. O. Participação, produção de conhecimento e pesquisa avaliativa: a inserção de diferentes atores em uma investigaçáo em saúde mental. Cadernos de Saúde Pública, Rio de Janeiro, v. 24, n. 11, p. 2671-2680, 2008.

GRIFFITHS, K. M.; JORM, A. F.; CHRISTENSEN, $\mathrm{H}$. Academic consumer researchers: a bridge between consumers and researchers. Australian and New Zealand Journal of Psychiatry, Asia, v. 38, n. 4, p. 191-196, 2004.

HABERMAS, J. Direito e democracia: entre faticidades e validade. Rio de Janeiro: Tempo Brasileiro, 1997.

HABERMAS, J. Some Further clarifications on the concept of communicative rationality. In: COOKE, M. On the pragmatics of communication. Cambridge: MIT Press, 1998. p. 307-342.

HANCOCK, N. et al. Participation of Mental health consumers in research: Training addressed and reliability assessed. Australian Occupational Therapy Journal, Australia, v. 59, n. 3, p. 218-224, 2012.

HAPPELL, B.; ROPER, C. Consumer participation in mental health research: articulating a model to guide practice. Australasian Psychiatry, Nova Zelândia, v. 15, n. 3, p. 237-241, 2007.

HONNETH, A. The Social dynamics of disrespect: situating critical theory today. In: DEWS, P. Habermas: a critical reader. Oxford: Blackwell, 1999. p. 320-337.

HOPKINS, H. Consumer participation in research. Journal of the Consumers Health Forum of Australia, Australia, v. 1, p. 1-2, 2008.

LOPES, R. E.; SILVA, C. R. O campo da educação e demandas para a terapia ocupacional no Brasil. Revista de Terapia Ocupacional da Universidade de São Paulo, São Paulo, v. 16, n. 1, p. 1-8, 2007.

MALFITANO, A. P. S. Campos e núcleos de intervençáo na terapia ocupacional social. Revista de Terapia Ocupacional da Universidade de São Paulo, São Paulo, v. 18, n. 3, p. 158-164, 2005.

MÂNGIA, E. F.; NICÁCIO, F. Terapia Ocupacional em Saúde Mental: Tendências Principais e desafios contemporâneos. In: DE CARLO, M. M. R. P.; BARTALOTTI, C. C. Terapia ocupacional no Brasil: fundamentos e perspectivas. São Paulo: Plexus, 2001. p. 63-80.

NING, L.; WEAVELL, W.; WOODHOUSE, S. Consumer participation in research. Psychiatric Disability Services of Victoria, Victoria, 2010. Disponível em: $<$ http://mheco.org.au/attachments/NewParadigm_Autumn2010_Consumer_Research.pdf>. Acesso em: 21 set. 2015 .

PRESOTTO, R. F. et al. Experiências brasileiras sobre participação de usuários e familiares na pesquisa em saú- 
de mental. Ciência e Saúde Coletiva, Rio de Janeiro, v. 18, n. 10, p. 2837-2845, 2013.

QUARENTEI, M. S. Terapia Ocupacional e a produção de vida. In: CONGRESSO BRASILEIRO DE TERAPIA OCUPACIONAL, 7., 2001, Porto Alegre. Anais... Porto Alegre: ABRATO, 2001. p. 1-3.

RAHMAN, M. A. The Theory and practice of participatory action research. In: BORDA, O. F. (Org.). The challenge of social change. Washington: Sage Studies in International Sociology, 1986. p. 107-132.

ROSE, D. Having a diagnosis is a qualification for the job. British Medical Journal, Londres, v. 326, n. 7402, p. 1331, 2003. http://dx.doi.org/10.1136/ bmj.326.7402.1331.
THIOLLENT, M. Metodologia da pesquisa-ação. São Paulo: Cortez, 2005

VASCONCELOS, E. M. Empoderamento de usuários e familiares em saúde mental e em pesquisa avaliativa/ interventiva: uma breve comparação entre a tradição anglo-saxônica e a experiência brasileira. Ciência e Saúde Coletiva, Rio de Janeiro, v. 18, n. 10, p. 2825-2835, 2013.

WOODALL, A.; HOWAR, L.; MORGAN, C. Barriers to participation in mental health research; Findings from the genetics and psychosis (GAP) study. International Review of Psychiatry, Londres, v. 23, n. 1, p. 31-40, 2011.

YOUNGSTROM, M. J. Occupational Therapy practice framework: the evolution of our professional languages. America Journal Occupational Therapy, Washington, v. 56, n. 6, p. 609-639, 2002.

\section{Contribuição dos Autores}

Tatiana Dimov contribuiu na concepção do texto, organização e análise das fontes, redação e revisão do texto. Ellen Cristina Ricci organizou e analisou as fontes, redigiu e revisou do texto. Ambas as autoras aprovaram a versão final do texto.

\section{Fonte de Financiamento}

O trabalho recebeu financiamento da CAPES, através de bolsa de doutorado de uma das autoras.

\section{Notas}

${ }^{1}$ Neste artigo, os usuários de serviços de saúde mental que participam de pesquisas acadêmicas serão também denominados pesquisadores comunitários, haja vista que desenvolvem o papel de pesquisadores a partir da valorização e do reconhecimento de sua inserção na comunidade. No entanto, entendemos que pessoas que vivenciam experiências de sofrimento mental podem se inserir na academia pelas mais diversas vias, inclusive tendo seu papel e lugar enquanto "pesquisador acadêmico" reconhecido, e escolhendo até pesquisar os mais diversos temas.

${ }^{2}$ Não encontramos tradução adequada para este termo na literatura em português. O termo é usado quando os pesquisadores se apropriam do saber dos participantes da pesquisa, sem que, aos mesmos, seja dado o devido crédito.

${ }^{3}$ Decidimos aqui manter os termos criados pela autora em inglês entre parênteses, oferecendo uma tradução livre dos mesmos no título de cada item.

${ }^{4}$ Termo utilizado para identificar o apoio ou a consulta a grupos ou partes interessadas na avaliaçáo e aplicação de projetos (tanto de empresas como de políticas governamentais). Aproxima-se do que aqui chamaríamos de participação da sociedade civil organizada, ou grupos de interesse na temática. Uma aproximação através do entendimento das autoras. 